Article

\title{
Two Lanthanide Metal-Organic Frameworks Based on Semi-Rigid T-Shaped Tricarboxylate Ligand: Syntheses, Structures, and Properties
}

\author{
Yun-Shan Xue ${ }^{1,2, *}$, Zhuo-Lin Chen ${ }^{1}$, Youzhen Dong ${ }^{1}$ and Wei-Wei Cheng ${ }^{3}$ \\ 1 School of Chemistry and Environmental Engineering, Yancheng Teachers University, Yancheng 224051, \\ Jiangsu, China; czling1998@163.com (Z.-L.C.); dongyouzhen@163.com (Y.D.) \\ 2 State Key Laboratory of Materials-oriented Chemical Engineering, Nanjing Tech University, \\ Nanjing 210009, China \\ 3 School of Chemistry and Bioengineering, Nanjing Normal University Taizhou College, Taizhou 225300, \\ China; 20111006@nnutc.edu.cn \\ * Correspondence: xueys@yctu.edu.cn
}

Received: 13 April 2019; Accepted: 4 May 2019; Published: 13 May 2019

\begin{abstract}
By using a semi-rigid tripodal ligand 5-(4-carboxybenzyloxy)isophthalic acid $\left(\mathrm{H}_{3} \mathrm{~L}\right)$ and lanthanide metal ions $\left(\mathrm{Nd}^{3+}, \mathrm{Tb}^{3+}\right)$, two novel lanthanide metal-organic frameworks, namely, $\left\{\left[\mathrm{Nd}_{2} \mathrm{~L}_{2}(\mathrm{DMF}) 4\right] \mathrm{DMF}\right\}_{\mathrm{n}}(\mathbf{1})$, and $\left\{\mathrm{TbL}(\mathrm{DMF})\left(\mathrm{H}_{2} \mathrm{O}\right)\right\}_{\mathrm{n}}(\mathbf{2})$, were synthesized under mild solvothermal conditions and structurally characterized by $\mathrm{X}$-ray single crystal diffraction. Compounds $\mathbf{1}$ and 2 are isostructural, in which $\mathrm{L}^{3-}$ ligands linked dinuclear lanthanide metal-carboxylate units to form non-interpenetrated 3D network with $(3,6)$-connected topology. Luminescent investigations reveal that compound 1 displays the near-infrared emission at room temperature, and compound $\mathbf{2}$ can be employed as selective probe for $\mathrm{Cr}_{2} \mathrm{O}_{7}{ }^{2-}$ anion in aqueous solution based on luminescence quenching. Moreover, compound 2 exhibits catalytic activity for cyclo-addition of $\mathrm{CO}_{2}$ and epoxides under relatively mild conditions.
\end{abstract}

Keywords: lanthanide metal-organic frameworks; crystal structures; luminescent property; catalytic performance

\section{Introduction}

Metal-organic frameworks (MOFs) as a class of new crystalline materials have drawn considerable interest recently, because of their widely potential applications in the fields of heterogeneous catalysis [1-4], chemical sensing [5-7], gas separation and storage [8-11], magnetism [12], photocatalytic materials [13], etc. Compared to traditional zeolite materials, MOFs possess tunable surfaces and pores, which are adjustable by choice of metal centers and modification of organic ligands. Hence, the structural features of the organic ligands, e.g., flexibility, functionality, symmetry, could greatly affect the performance and structure of the MOFs. Among various organic ligands, semi-rigid polycarboxylate ligands have been demonstrated to be good candidates for the construction of multifarious MOFs, which could adopt versatile conformations to meet different coordination environmental requirements, leading to unpredictable and intriguing framework topologies. So far, a few functional porous MOFs based on semi-rigid polycarboxylates have been widely reported. Taking the above into account, we chose a semi-rigid tricarboxylate ligand 5-(4-carboxybenzyloxy) isophthalic acid $\left(\mathrm{H}_{3} \mathrm{~L}\right)$. The ligand exhibits a great variety of coordination modes to metal ions, due to the rigid benzoic acid and isophthalic acid moieties. Moreover, the $\mathrm{H}_{3} \mathrm{~L}$ features certain flexibility, owing to the presence of $-\mathrm{CH}_{2} \mathrm{O}$ - group that can twist around to meet the requirement of the coordination environment. Among enormous MOFs, lanthanide metal-organic frameworks ( $\mathrm{Ln}-\mathrm{MOFs}$ ) have attracted increasing attention 
as special branch of functional MOFs because of their unique physical properties such as color-pure luminescence, long excited-state luminescence lifetimes, distinct stokes shifts, typical sharp emission peaks, and large paramagnetism [14-16]. The lanthanide ions are different from other metal ions, mainly included the following aspects: (i) lanthanide ions could emit light over narrow wavelength ranges and show high fluorescence quantum yields; (ii) the lanthanide family of ions usually has high coordination number, e.g., eight-, nine-, ten-, eleven-, and twelve-coordinated with oxygen to yield versatile clusters; and (iii) the luminescence of $\mathrm{Ln}^{3+}$ ions could be effectively sensitized when coordinated with suitable conjugated chromophores by tuning $\mathrm{f}-\mathrm{f}$ or $\mathrm{f}-\mathrm{d}$ electronic transition, the so-called "antenna effect" [17-19].

Chemical fixation and conversion of carbon dioxide $\left(\mathrm{CO}_{2}\right)$ have been a hot area of research because it was promising on solving the issue of greenhouse effect primarily caused by rapidly increasing $\mathrm{CO}_{2}$ levels in the atmosphere. Great effort has been devoted to reusing $\mathrm{CO}_{2}$ to synthesize valuable raw materials, because $\mathrm{CO}_{2}$ is nontoxic, inexpensive, abundant, and important $\mathrm{C} 1$ building block. Some examples show that MOFs could be ideal catalysts in the cyclo-addition reaction of $\mathrm{CO}_{2}$ with epoxides to form cyclic carbonates, owing to abundant catalytic active sites formed by inorganic metal units and organic ligands (e.g., metal-centered Lewis acid sites, Brønsted sites), which play a significant role in catalysis reactions. Furthermore, MOF-based catalysts exhibit excellent separability and circulation, thus there would be a very potential heterogeneous catalyst and have good application prospects in industry [20].

With the above considerations in mind, two Ln-MOFs, $\left\{\left[\mathrm{Nd}_{2} \mathrm{~L}_{2}(\mathrm{DMF})_{4}\right] \mathrm{DMF}\right\}_{\mathrm{n}}(\mathbf{1})$, and $\left\{\mathrm{TbL}(\mathrm{DMF})\left(\mathrm{H}_{2} \mathrm{O}\right)\right\}_{\mathrm{n}}(2)$, based on the semi-rigid tripodal ligand $\mathrm{H}_{3} \mathrm{~L}$ were obtained $\left(\mathrm{H}_{3} \mathrm{~L}=\right.$ 5-(4-carboxybenzyloxy)isophthalic acid). Compounds $\mathbf{1}$ and $\mathbf{2}$ are isostructural, and have been determined by single-crystal X-ray diffraction. Luminescence explorations reveal that $\mathrm{Tb}^{3+}$-based emission peaks of compound 2 could be selectively quenched by chromium (VI) anion, which suggested that compound 2 could serve as a promising luminescent probe for chromium (VI) anions. In addition, the studies have shown that compound 2 could catalyze the cyclo-addition of $\mathrm{CO}_{2}$ and epoxides under mild conditions to form cyclic carbonates efficiently.

\section{Experimental Section}

\subsection{Synthesis of Compound 1}

A mixture of $\mathrm{Nd}\left(\mathrm{NO}_{3}\right)_{3} \cdot 6 \mathrm{H}_{2}(0.035 \mathrm{~g}, 0.09 \mathrm{mmol})$ and $\mathrm{H}_{3} \mathrm{~L}(0.020 \mathrm{~g}, 0.06 \mathrm{mmol})$ in DMF $(2 \mathrm{~mL})$, $\mathrm{EtOH}(0.5 \mathrm{~mL})$ and $150 \mu \mathrm{L}$ of $\mathrm{HNO}_{3}(2 \mathrm{~mol} / \mathrm{L})$ was sealed in a $25 \mathrm{~mL}$ Teflon-lined stainless steel autoclave. The mixture was heated at $80{ }^{\circ} \mathrm{C}$ for $48 \mathrm{~h}$, and then cooled to room temperature. Purple block single crystals of 1 were collected in ca. $28 \%$ yield based on $\mathrm{H}_{3} \mathrm{~L}$. Elemental analysis for $\mathrm{C}_{47} \mathrm{H}_{50} \mathrm{~N}_{5} \mathrm{Nd}_{2} \mathrm{O}_{19}$, calcd (\%): C, 44.19; H, 3.95; and N, 5.48. Found (\%): C, 43.28; H, 4.33; and N, 5.19.

\subsection{Synthesis of Compound 2}

A mixture of $\mathrm{Tb}\left(\mathrm{NO}_{3}\right)_{3} \cdot 6 \mathrm{H}_{2} \mathrm{O}(0.035 \mathrm{~g}, 0.08 \mathrm{mmol})$, and $\mathrm{H}_{3} \mathrm{~L}(0.020 \mathrm{~g}, 0.06 \mathrm{mmol})$ in DMF $(2 \mathrm{~mL})$ plus of $\mathrm{H}_{2} \mathrm{O}(1 \mathrm{~mL})$ was sealed in a $25 \mathrm{~mL}$ Teflon-lined stainless steel autoclave. The steel autoclave was heated at $80^{\circ} \mathrm{C}$ for $48 \mathrm{~h}$, and then cooled to room temperature. Colorless block single crystals of 2 were collected in ca. $24 \%$ yield based on $\mathrm{H}_{3} \mathrm{~L}$. Elemental analysis for $\mathrm{C}_{19} \mathrm{H}_{18} \mathrm{NO}_{9} \mathrm{~Tb}$, calcd (\%): C, 40.51; H, 3.22; and N, 2.49. Found (\%): C, 39.87; H, 3.47; and N, 2.73.

\section{Results and Discussion}

\subsection{Synthesis}

Two title compounds $\mathbf{1}$ and $\mathbf{2}$ were synthesized by using solvothermal method, inspired by the paper by Ma et al. [21]. The semi-rigid ligand $\mathrm{H}_{3} \mathrm{~L}$ and lanthanide nitrate salts are dissolved in a mixture of $\mathrm{DMF}, \mathrm{EtOH}$, and $\mathrm{H}_{2} \mathrm{O}$. Then, the resulting mixture was left undisturbed at $80^{\circ} \mathrm{C}$ for 2 days. 
The reaction system was then gradually cooled to room temperature. The difference between our work and the procedures followed by Ma et al. is that we have used lanthanide nitrate salts and Ma et al. have reported Ln-MOFs by using lanthanide chlorides. It is well-known that many factors can affect the formation of the final products during a specific solvothermal approach, such as the type of metal salts, counter-anions, reaction temperature, $\mathrm{pH}$ values, the type of solvent, and starting concentrations of reactants [22]. In our case, a series of contrast experiments have been performed to explore the influence of reaction conditions on identity and crystallinity of the final products. The results show that the type of metal salts play vital role in reaction system. We employed lanthanide chloride compounds to synthesize Ln-MOFs under different reaction conditions of Ma et al. However, the resulting crystals were already known complexes. In addition, the result of contrast experiments shows that a slight difference in temperature and the proportion of mixed solvent of $\mathrm{DMF}, \mathrm{H}_{2} \mathrm{O}$, and $\mathrm{EtOH}$ have less influenced on crystallinity of crystals.

\subsection{Crystal Structure Descriptions}

The single-crystal X-ray diffraction structure analyses indicate that compounds $\mathbf{1}$ and $\mathbf{2}$ are isostructural. Their differences lie in metal salts used ( $\mathrm{Nd}$ and $\mathrm{Tb}$ for $\mathbf{1}$ and $\mathbf{2}$, respectively). It should be noted that the coordinated solvent molecules in compound $\mathbf{2}$ are slightly different from compound 1. As a representative example, only the structure description of compound $\mathbf{1}$ will be discussed here in detail. Compound 1 crystallizes in centrosymmetric monoclinic C2/c space group (No. 15, standard setting). Each asymmetric unit consists of one fully deprotonated ligand $\mathrm{H}_{3} \mathrm{~L}$, one crystallographically individual Nd(III) ion, two coordinated DMF molecules and one DMF solvent molecule (half-occupied). However, the asymmetric unit of compound 2 contains one $\mathrm{L}^{3-}$ organic ligand, one $\mathrm{Tb}(\mathrm{III})$ ion, one coordinated DMF molecule and one coordinated water molecule. As shown in Figure 1, the resulting three-dimensional (3D) framework of $\mathbf{1}$ is constructed from dinuclear metal-carboxylate cluster $\left\{\mathrm{Nd}_{2}(\mathrm{COOR})_{6}(\mathrm{DMF})_{4}\right\}$ and organic ligand $\mathrm{L}^{3-}$ as building units. Each $\mathrm{Nd}$ center is nine-coordinated with two oxygen atoms from two bidentate carboxylate groups of two $\mathrm{L}^{3-}$ ligands, three oxygen atoms from two chelating bidentate carboxylate groups of the other two $\mathrm{L}^{3-}$ ligands, two oxygen atoms from one chelating carboxylate group of $\mathrm{L}^{3-}$ ligand (Nd-O distances ranging from 2.419(4) to 2.674(4) $\mathrm{A}$ ), and two oxygen atoms from two coordinated DMF molecules (Nd-O distance of 2.428(5) and 2.500(5) $\AA$ ). The coordination environment of $\mathrm{Nd}$ center can be considered as a distorted monocapped square antiprism geometry (Figure 1a). Two neighboring $\mathrm{Nd}$ centers ( $\mathrm{Nd} 1$ and symmetry-related $\mathrm{Nd} 1 \mathrm{~A}$ ) are linked by two carboxyl groups in a bridging and chelating mode and two carboxyl groups via bidentate coordination mode to form dinuclear $\left\{\mathrm{Nd}_{2}(\mathrm{COOR})_{6}(\mathrm{DMF})_{4}\right\}$ cluster, which connects six carboxylate groups from six independent $\mathrm{L}^{3-}$ ligands. Each fully deprotonated $\mathrm{L}^{3-}$ ligand adopts a $\mu_{5}$ coordination mode via three carboxyl groups linking metal clusters $\left\{\mathrm{Nd}_{2}(\mathrm{COOR})_{6}(\mathrm{DMF})_{4}\right\}$ in bridging chelation, bidentate and chelation coordination modes (Figure 1b). In order to meet practical coordination configuration requirement, carboxyl groups rotate around the flexible alkyl bond and two benzene rings of $\mathrm{L}^{3-}$ are not in the same plane with dihedral angles of $17.48^{\circ}$.

The rod-shaped clusters $\left\{\mathrm{Nd}_{2}(\mathrm{COOR})_{6}(\mathrm{DMF})_{4}\right\}$ are interconnected by $\mathrm{L}^{3-}$ ligands to form a three-dimensional (3D) framework with two kinds of 1D channels along $\boldsymbol{b}$ (i.e., small and large rectangular channels) and $c$ (i.e., small oval channels and large diamond channels) directions. As depicted in Figure 2, the coordinated DMF molecules protrude into the channels in the rectangular and diamond channels, resulting in reduced dimensionality of channels. These channels are occupied by guest DMF molecules, which could be located from the single-crystal X-ray diffraction data. The void volume is estimated by PLATON program [23] to be about $53.6 \%$ of the unit cell volume of $5566.9 \AA^{3}$ (coordinated and guest DMF molecules not taken into account) and $22.6 \%$ of the unit cell volume (guest DMF molecule not taken into account).

To better understand the architecture of compound 1, topological analysis (i.e., reducing multi-dimensional structures to simple node-and-linker nets) was performed using the TOPOS program [24]. It became evident that each $\mathrm{L}^{3-}$ ligand can be simplified as 3-connected node with 
point symbol $\left\{4^{2} 6\right\}$; the $\left\{\mathrm{Nd}_{2}(\mathrm{COOR})_{6}(\mathrm{DMF})_{4}\right\}$ cluster is viewed as a pentagonal dodecahedron and considered as 6-connected node, each of which is connected by six $\mathrm{L}^{3-}$ ligands. On the basis of above simplification model, the whole framework of compound $\mathbf{1}$ could be simplified as 2-nodal $(3,6)$-connected net with the topology $f l u-3,6-C 2 / c$, which is a subnet of $f l u$ according to TOPOS analysis. The point symbol for net is $\left\{4^{2} \cdot 6\right\}_{2}\left\{4^{4} \cdot 6^{2} \cdot 8^{7} \cdot 10^{2}\right\}$ (Figure 3).

(a)

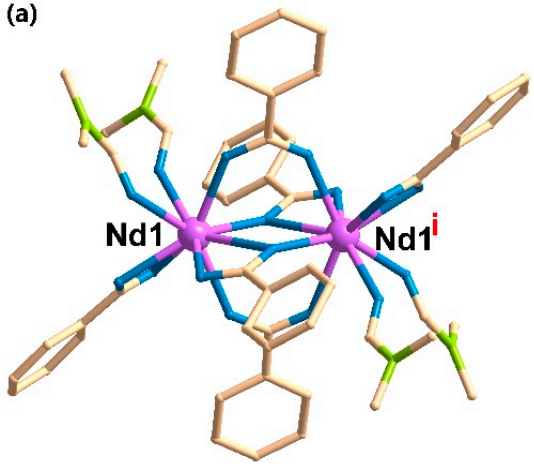

(b)

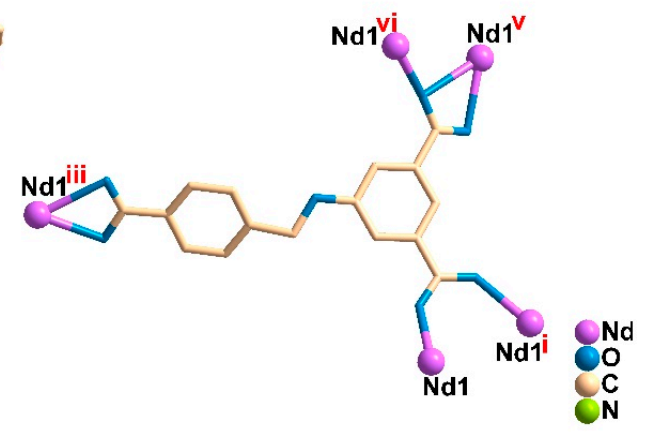

Figure 1. The coordination environment of (a) inorganic building units $\left\{\mathrm{Nd}_{2}(\mathrm{COOR})_{6}(\mathrm{DMF})_{4}\right\}$ and (b) organic ligand $\mathrm{L}^{3-}$.

(a)

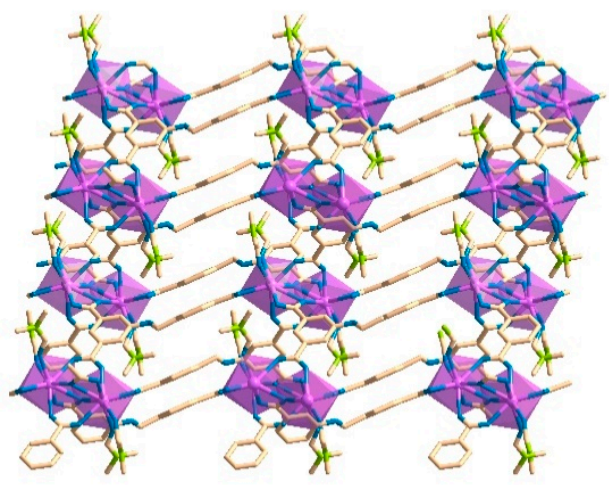

(b)

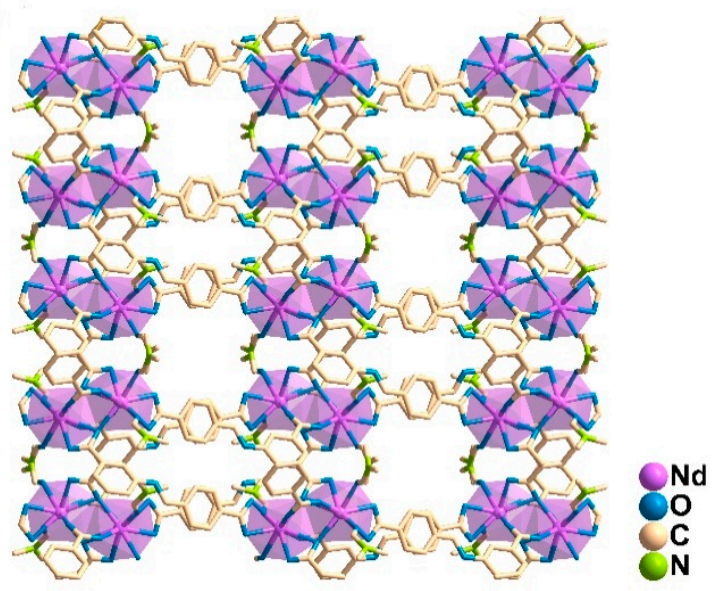

Figure 2. (a) The structure of $\mathbf{1}$ with channels along the $\boldsymbol{b}$ axe; and (b) the structure of $\mathbf{1}$ with channels along the $c$ axe.

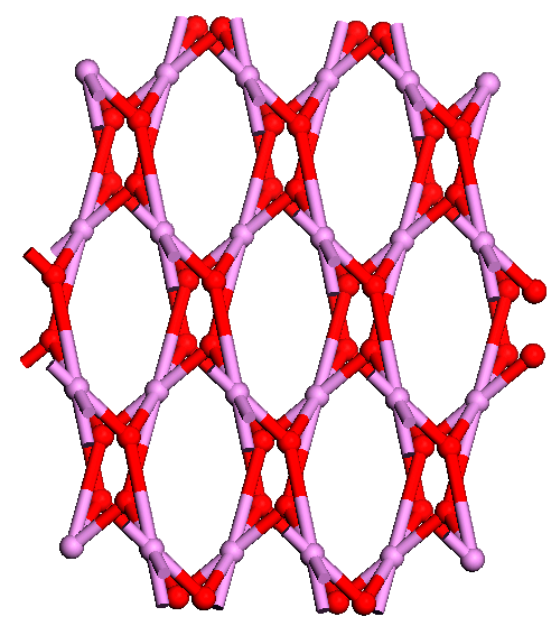

Figure 3. Schematic representation of the $(3,6)$-connected net of compound $\mathbf{1}$. 


\subsection{Thermal Stability Analysis}

Thermogravimetric analyses (TGA) were performed to investigate the thermal stabilities of compounds 1 and 2 using single crystal samples under $\mathrm{N}_{2}$ atmosphere. As shown in Figure S1, compounds 1 and 2 exhibited a similar profile. Compound 1 showed a weight loss of $27.6 \%$ at $20-450{ }^{\circ} \mathrm{C}$, assigned to loss of guest and coordinated DMF molecules (calc. $28.5 \%$ ). Further heating, the structure began to collapse and decomposed into metal oxide. TGA of compound 2 displayed a weight loss of $15.5 \%$ in the temperature range of $20-400{ }^{\circ} \mathrm{C}$ due to the removal of coordinated water and DMF molecules (calc. 16.3\%). Higher temperature resulted in the collapse of the structure and decomposition of the organic ligand.

\subsection{Photoluminescent Properties}

The solid state photoluminescent spectra of compounds $\mathbf{1}$ and $\mathbf{2}$ were examined at room temperature. As illustrated in Figure S2, the free $\mathrm{H}_{3} \mathrm{~L}$ ligand exhibits the maximum emission band at $363 \mathrm{~nm}\left(\lambda_{\mathrm{ex}}=290 \mathrm{~nm}\right)$, which is attributable to the $\pi^{*} \rightarrow \mathrm{n}$ or $\pi^{*} \rightarrow \pi$ transitions [25,26]. The near-infrared (NIR) emission of the $\mathrm{Nd}^{3+}$ ion in compound 1 exhibits characteristic peaks at 1056 and $1330 \mathrm{~nm}$ upon excited at $808 \mathrm{~nm}$ by Nd:YAG laser, which can be assigned to the ${ }^{4} \mathrm{~F}_{3 / 2} \rightarrow{ }^{4} \mathrm{I}_{11 / 2}$, ${ }^{4} \mathrm{~F}_{3 / 2} \rightarrow{ }^{4} \mathrm{I}_{13 / 2}$ transitions of the $\mathrm{Nd}^{3+}$ ions, respectively $[27,28]$ (Figure 4).

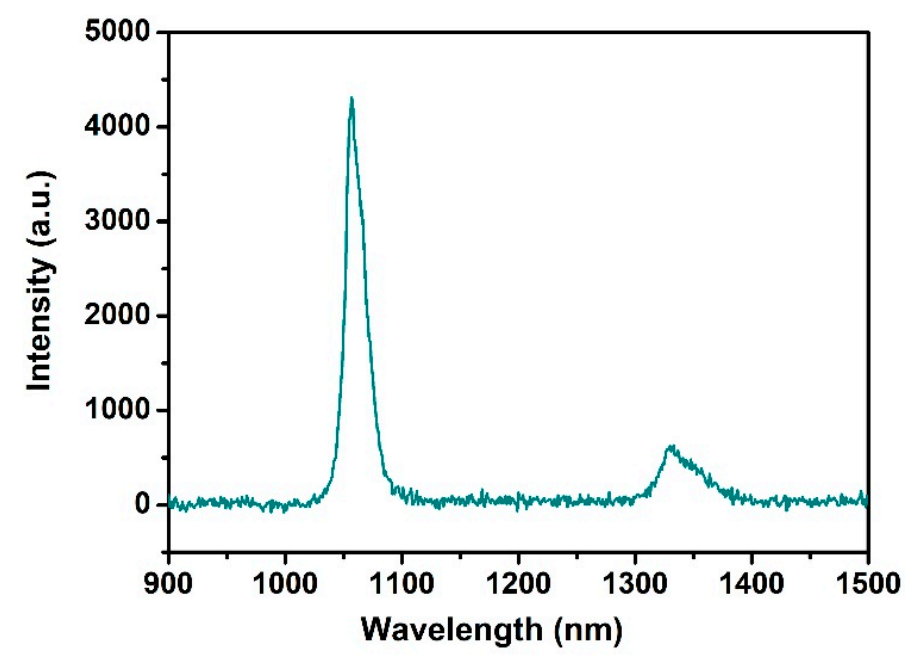

Figure 4. The NIR emission of compound 1 excited at $808 \mathrm{~nm}$ by laser.

$\mathrm{Tb}(\mathrm{III})$-based compound 2 emits green luminescence visible to the naked eye under UV light $\left(\lambda_{\mathrm{ex}}=310 \mathrm{~nm}\right)$ and exhibits the characteristic emission peaks for $\mathrm{Tb}(\mathrm{III})$ ion observed at 489, 544, 584, and $620 \mathrm{~nm}$ (Figure S3), which could be ascribed to the transitions of ${ }^{5} \mathrm{D}_{4} \rightarrow{ }^{7} \mathrm{~F}_{\mathrm{J}}(\mathrm{J}=6-3)$ [29-31]. The most intense emission peak corresponds to hypersensitive ${ }^{5} \mathrm{D}_{4} \rightarrow{ }^{7} \mathrm{~F}_{5}$ transition at $544 \mathrm{~nm}[32,33]$. The photoluminescent spectra of 2 exhibits characteristic emission bands of $\mathrm{Tb}$ (III) ion and the ligand-related emission peaks are not observable, which indicates energy transfer from $\mathrm{H}_{3} \mathrm{~L}$ ligand to the $\mathrm{Tb}$ (III) ion during photoluminescence [34]. UV-Vis absorption spectra of compounds $\mathbf{1}$ and $\mathbf{2}$ are displayed in Figure S4. It is well established that the construction of Ln-MOFs not only have a significance to extend the Ln-MOFs family, but also allow exploiting them as fluorescent probes because of their remarkable luminescence properties and feature distinct advantages in sensitivity, operability and response time. Recently, Ln-MOFs employed as chemical sensors have been widely studied, and mainly focused on the fluorescence detection of small organic molecules [35,36], cations [37], and anions [38]. However, the detection of chromium(VI) anion species $\left(\mathrm{Cr}_{2} \mathrm{O}_{7}{ }^{2-}\right.$ or $\left.\mathrm{CrO}_{4}{ }^{2-}\right)$ are poorly reported, which are commonly poisonous in wastewater and cause environment pollution and be harmful to the livings' health. This thus urgently calls for more new luminescent sensors to detect chromium(VI) anions. 
Based on the above, a series of spectroscopic experiments were conducted in water solutions including different anions to explore the sensing ability of compound $\mathbf{2}$. The finely ground samples $(10 \mathrm{mg})$ were dispersed in $1.9 \mathrm{~mL}$ aqueous solution by using ultrasonic method to form steady suspension solution, and then $100 \mu \mathrm{L} \mathrm{K} \mathrm{m}$ solution $\left(0.1 \mathrm{~mol} / \mathrm{L}, \mathrm{X}=\mathrm{Br}^{-}, \mathrm{Cl}^{-}, \mathrm{I}^{-}, \mathrm{SCN}^{-}, \mathrm{IO}_{3}^{-}, \mathrm{NO}_{3}^{-}, \mathrm{BrO}_{3}^{-}, \mathrm{ClO}_{3}{ }^{-}\right.$, $\mathrm{SO}_{4}{ }^{2-}, \mathrm{CO}_{3}{ }^{2-}, \mathrm{MnO}_{4}{ }^{-}, \mathrm{Cr}_{2} \mathrm{O}_{7}{ }^{2-}$, and $\mathrm{CrO}_{4}{ }^{2-}$ ) was slowly dropped into the above suspension solution $(0.005 \mathrm{~mol} / \mathrm{L})$. These resultant suspensions were investigated by using fluorescence spectrophotometer. As illustrated in Figure 5a, the obtained fluorescence spectra still showed characteristic emission peaks of $\mathrm{Tb}$ (III) ion and only the strongest ${ }^{5} \mathrm{D}_{4} \rightarrow{ }^{7} \mathrm{~F}_{5}$ transition of $\mathrm{Tb}^{3+}$ centered at $544 \mathrm{~nm}$ were recorded in Figure $5 \mathrm{~b}$. The results indicate that the emission intensities of different suspensions vary with anions. Obviously, most anions, such as halide ions, $\mathrm{SCN}^{-}, \mathrm{IO}_{3}{ }^{-}, \mathrm{NO}_{3}{ }^{-}, \mathrm{SO}_{4}{ }^{2-}, \mathrm{CO}_{3}{ }^{2-}, \mathrm{ClO}_{3}{ }^{-}$, and $\mathrm{BrO}_{3}{ }^{-}$display no obvious or negligible influence on the intensity. The addition of $\mathrm{MnO}_{4}{ }^{-}$lead to the fluorescence intensity slightly decrease, while $\mathrm{Cr}_{2} \mathrm{O}_{7}{ }^{2-}, \mathrm{CrO}_{4}{ }^{2-}$ exhibit significantly quenching behavior, indicating that compound 2 could act as a promising chemical sensor toward $\mathrm{Cr}(\mathrm{VI})$ in aqueous solution. Since the $\mathrm{Cr}_{2} \mathrm{O}_{7}{ }^{2-}$ anion showed the strongest quenching effect on the intensity of compound 2, it was chosen as the representative to investigate the fluorescence sensing behaviors.

(a)

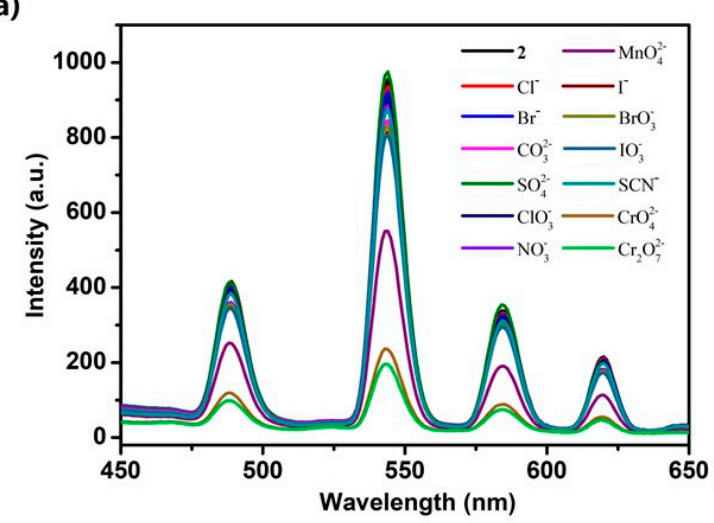

(b)

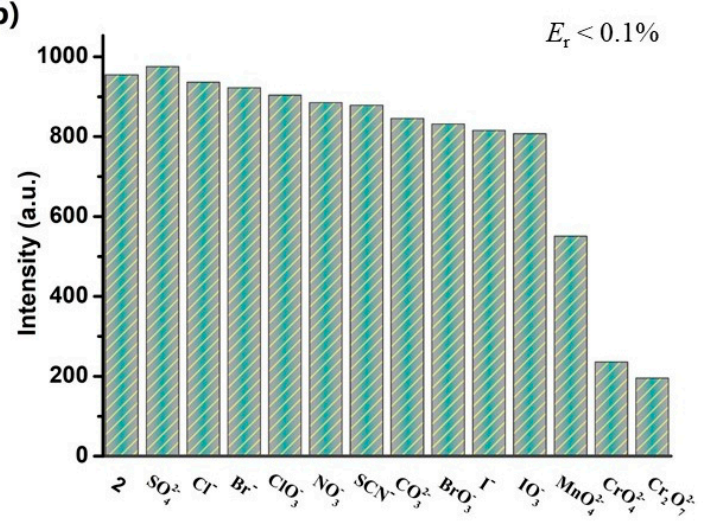

Figure 5. (a) The fluorescence spectra for compound 2 after the samples were dispersed in 0.005 $\mathrm{mol} / \mathrm{L}$ concentration of aqueous solutions containing different metal ions; and (b) the enhancement or quenching efficiency histogram of compound 2.

To explore the sensing sensitivity of compound 2 as $\mathrm{Cr}_{2} \mathrm{O}_{7}{ }^{2-}$ probe, different concentrations of $\mathrm{Cr}_{2} \mathrm{O}_{7}{ }^{2-}\left(10^{-5}-10^{-2} \mathrm{~mol} / \mathrm{L}\right)$ experiments were then performed in aqueous solution. The fluorescence intensity of compound 2 gradually reduced with increasing addition of $\mathrm{Cr}_{2} \mathrm{O}_{7}{ }^{2-}$, and the reduced intensity could be clearly distinguished with $1 \times 10^{-5} \mathrm{~mol} / \mathrm{L} \mathrm{Cr}_{2} \mathrm{O}_{7}{ }^{2-}$ solution, indicating that detection limit of compound 2 could reach $10^{-5} \mathrm{~mol} / \mathrm{L}$ as a fluorescent sensor for detecting $\mathrm{Cr}_{2} \mathrm{O}_{7}{ }^{2-}$ (Figure 6a). Moreover, the quenching efficiency was calculated by $\left(I_{0}-I\right) / I_{0} \times 100 \%$ equation, where $I_{0}$ and $I$ represent the intensity of compound 2 before and after adding $\mathrm{Cr}_{2} \mathrm{O}_{7}{ }^{2-}$, respectively. The quenching efficiency could reach $97.2 \%$ when the concentration of $\mathrm{Cr}_{2} \mathrm{O}_{7}{ }^{2-}$ increased to $0.02 \mathrm{~mol} / \mathrm{L}$ (Figure $6 \mathrm{~b}$ ).

Furthermore, we used the Stern-Volmer (S-V) equation to generate a plot of fluorescence intensity vs the concentration of $\mathrm{Cr}_{2} \mathrm{O}_{7}{ }^{2-}$ in the low concentration range of $0-10^{-3} \mathrm{~mol} / \mathrm{L}, \mathrm{I}_{0} / \mathrm{I}=\mathrm{KSV}_{\mathrm{SV}}\left[\mathrm{Cr}_{2} \mathrm{O}_{7}{ }^{2-}\right]+$ $1\left(K_{\mathrm{SV}}\right.$ is quenching rate constant, and $\left[\mathrm{Cr}_{2} \mathrm{O}_{7}{ }^{2-}\right]$ represents the concentration of $\left.\mathrm{Cr}_{2} \mathrm{O}_{7}{ }^{2-}\right)$. The S-V plot reveals that there exists a nearly linear correlation at low concentrations $\left(R^{2}=0.9972\right)$, which could be fitted as $I_{0} / I=K_{\mathrm{SV}}\left[\mathrm{Cr}_{2} \mathrm{O}_{7}{ }^{2-}\right]+1.01$. The $K_{\mathrm{SV}}$ value is calculated to be $2.26 \times 10^{3} \mathrm{~L} / \mathrm{mol}$ (Figure 7), indicating that the $\mathrm{Cr}_{2} \mathrm{O}_{7}^{2-}$ has a high quenching efficiency on the luminescence of compound 2. 
(a)

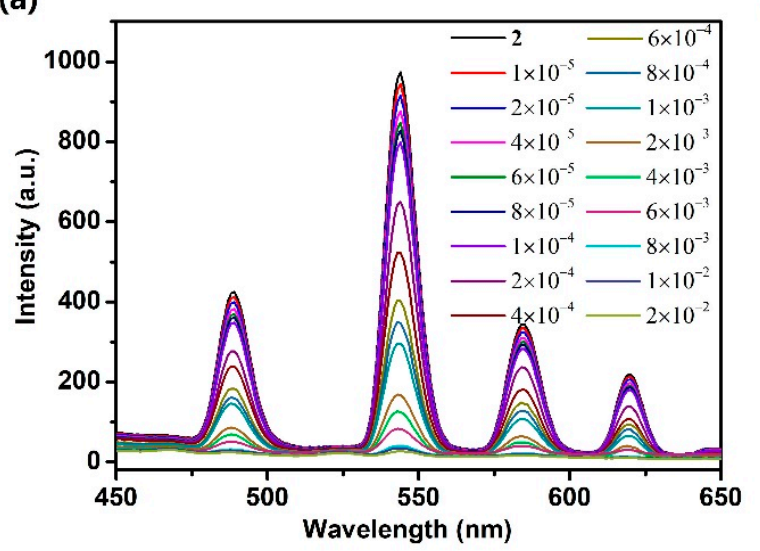

(b)

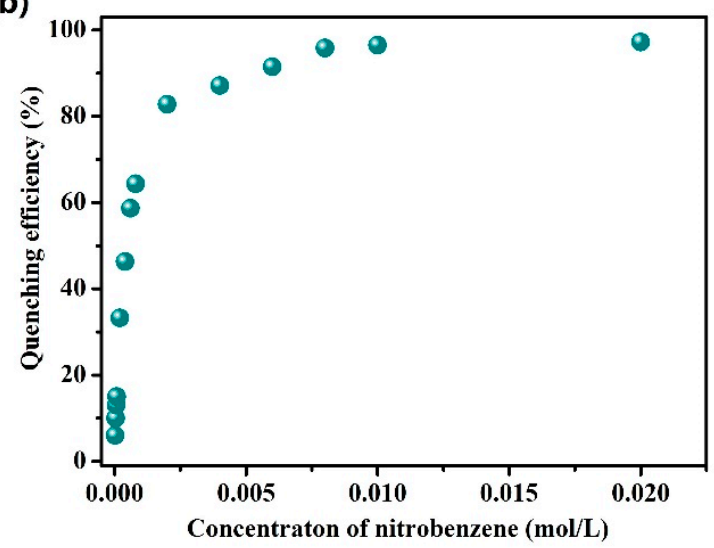

Figure 6. (a) The emission spectra of compound 2 dispersed in aqueous with different concentrations of $\mathrm{Cr}_{2} \mathrm{O}_{7}{ }^{2-}$; and (b) dependence of the quenching efficiency on the concentration of $\mathrm{Cr}_{2} \mathrm{O}_{7}{ }^{2-}$.

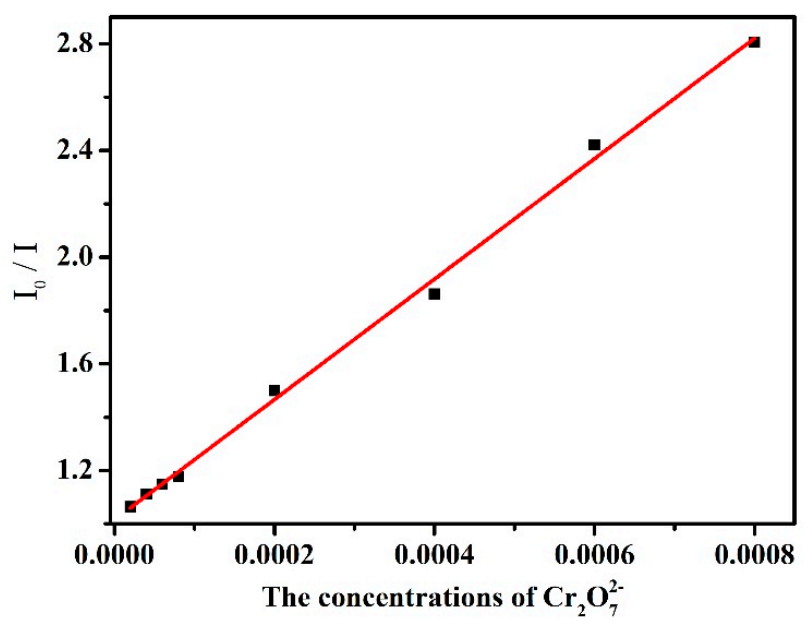

Figure 7. Stern-Volmer plot of compound 2 with different concentrations of $\mathrm{Cr}_{2} \mathrm{O}_{7}{ }^{2-}$.

\subsection{Catalytic Performance}

Recently, it has been reported that $\mathrm{Tb}^{3+}$ sites in Tb-based MOFs could act as Lewis acidic centers [39]. Therefore, we explored the catalytic activity of compound $\mathbf{2}$, and here the conversion of $\mathrm{CO}_{2}$ into cyclic carbonates was studied. The catalytic performance of compound 2 was investigated by using propylene oxide (PO) as the model substrate to explore the optimized catalytic reaction condition, and the corresponding results were shown in Table 1 . The catalytic reaction was firstly conducted using compound $2(2 \mathrm{~mol} \%)$ and tetra- $n$-butyl-ammonium bromide $\left(n-\mathrm{Bu}_{4} \mathrm{NBr}, 2.5 \mathrm{~mol} \%\right)$ as co-catalyst under relatively mild condition $\left(0.2 \mathrm{MPa}\right.$ and $\left.30^{\circ} \mathrm{C}\right)$. The desired product propylene carbonate (PC) was obtained after different reaction time (12 h, $24 \mathrm{~h}$, and $36 \mathrm{~h})$, and the yield could reach $4.7 \%, 8.3 \%$, and $9.9 \%$, respectively (entries 1, 2, and 3 in Table 1 ). The results indicated that catalytic activity of compound 2 was poor under these conditions. Subsequently, the reaction pressure was increased to $1.0 \mathrm{MPa}$, the $\mathrm{PO}$ conversion reached $42.8 \%$ (entry 4). When the reaction temperature was increased to $70^{\circ} \mathrm{C}$ and the pressure was kept at $1.0 \mathrm{MPa}$, the reaction could be completed within $12 \mathrm{~h}$. In these preliminary studies, the results indicated that the higher temperature and pressure could facilitate the reaction process.

As shown in Figure 8a, $\mathrm{PO}$ conversion increased from 30 to $70{ }^{\circ} \mathrm{C}$ under $1.0 \mathrm{MPa}$ pressure with the reaction time of $12 \mathrm{~h}$. Further increasing temperature, the PO conversion was not obviously increased. In addition, the yield increased with the prolonged reaction time. It is noteworthy that the reaction time was prolonged to $24 \mathrm{~h}$, the reaction could be almost completed at a lower temperature of $60^{\circ} \mathrm{C}$ (entry 5 in Table 1). $\mathrm{CO}_{2}$ pressure was also important to influence the cycloaddition of $\mathrm{PO}$ and $\mathrm{CO}_{2}$. 
As is seen from Figure $8 \mathrm{~b}$, the PO conversion increased with $\mathrm{CO}_{2}$ pressure 0.2 to $1 \mathrm{MPa}$ and leveled in the pressure range of 1-2 MPa. Further increasing $\mathrm{CO}_{2}$ pressure ( $>2 \mathrm{MPa}$ ) could reduce the PC yield, which might be ascribed to the disruption of the lattice structure at a high pressure. In addition, the yields were very low when compound 2 or $n$ - $\mathrm{Bu}_{4} \mathrm{NBr}$ was solely used as catalyst under the conditions of $1.0 \mathrm{MPa}$ and $70{ }^{\circ} \mathrm{C}$ for $12 \mathrm{~h}$ (entries 7 and 8). However, the PO conversion was remarkably enhanced when compound 2 and $n-\mathrm{Bu}_{4} \mathrm{NBr}$ were employed simultaneously. It is known that compound $\mathbf{2}$ and $n-\mathrm{Bu}_{4} \mathrm{NBr}$ have excellent synergetic effect in the catalytic system of $\mathrm{CO}_{2}$ cyclo-addition reaction [40-43]. In conclusion, the optimized reaction conditions should be $70{ }^{\circ} \mathrm{C}$ and $1.0 \mathrm{MPa} \mathrm{CO}_{2}$ pressure with $2 \mathrm{~mol} \%$ catalyst 2 and $2.5 \mathrm{~mol} \%$ co-catalyst $n$-Bu $\mathrm{NBr}_{4}$ for $12 \mathrm{~h}$.

Table 1. Cyclo-addition of $\mathrm{CO}_{2}$ with propylene oxide under different reaction conditions.

\begin{tabular}{|c|c|c|c|c|}
\hline Entry & Temperature $\left({ }^{\circ} \mathrm{C}\right)$ & Pressure (MPa) & Time (h) & Yield (\%) \\
\hline 1 & 30 & 0.2 & 12 & 4.7 \\
\hline 2 & 30 & 0.2 & 24 & 8.3 \\
\hline 3 & 30 & 0.2 & 36 & 9.9 \\
\hline 4 & 30 & 1.0 & 12 & 42.8 \\
\hline 5 & 60 & 1.0 & 24 & 98.7 \\
\hline 6 & 70 & 1.0 & 12 & $>99$ \\
\hline $7^{[\mathrm{a}]}$ & 70 & 1.0 & 12 & 10.7 \\
\hline $8^{[b]}$ & 70 & 1.0 & 12 & 17.3 \\
\hline $9[c]$ & 70 & 1.0 & 12 & 94.2 \\
\hline
\end{tabular}

Reaction conditions: $\mathrm{PO}(20 \mathrm{mmol})$, compound $2(2 \mathrm{~mol} \%), n-\mathrm{Bu} 4 \mathrm{NBr}(0.5 \mathrm{mmol}, 2.5 \mathrm{~mol} \%)$ under different conditions. Determined by ${ }^{1} \mathrm{H}$ NMR spectroscopy. ${ }^{[\mathrm{a}]}$ In the absence of $n$-Bu $\mathrm{Bu}_{4} \mathrm{NBr}$. ${ }^{[\mathrm{b}]}$ In the absence of 2 . [c] The yield of the $4^{\text {th }}$ cycling.

(a)

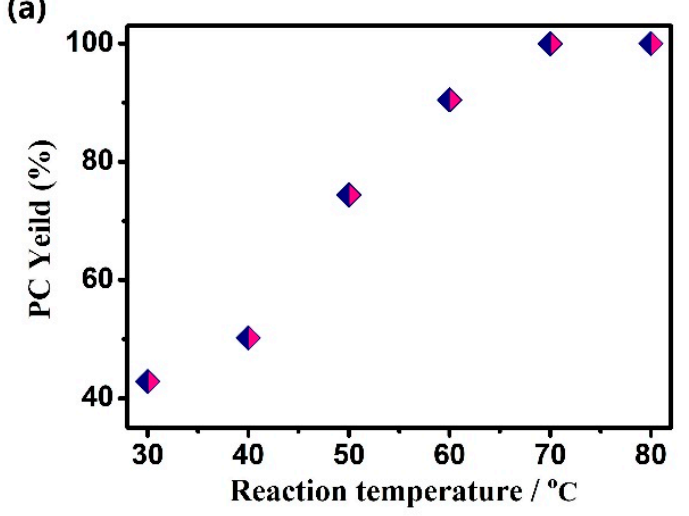

(b)

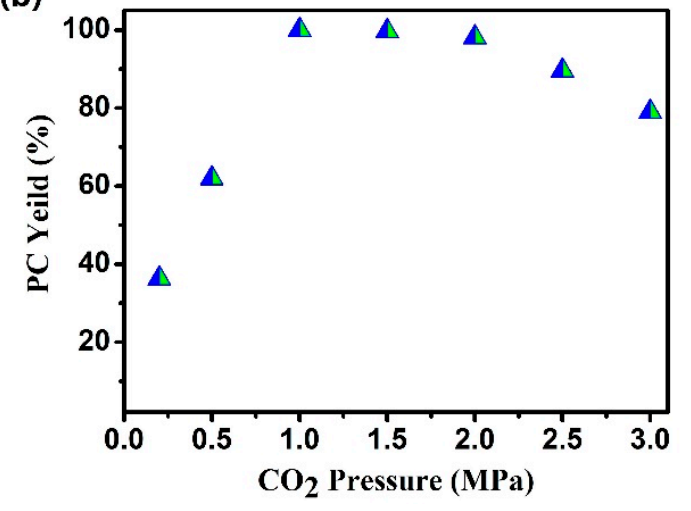

Figure 8. Influence of (a) reaction temperature $\left(P\left(\mathrm{CO}_{2}\right)=1.0 \mathrm{MPa}, t=12 \mathrm{~h}\right)$, and (b) $\mathrm{CO}_{2}$ pressure $\left(\mathrm{T}=70^{\circ} \mathrm{C}, t=12 \mathrm{~h}\right.$ ) on the cyclo-addition of $\mathrm{CO}_{2}$ with PO. Other reaction conditions: $\mathrm{PO}(20 \mathrm{mmol})$; compound 2 (2 mol\%); $n$-Bu ${ }_{4} \mathrm{NBr}(2.5 \mathrm{~mol} \%)$.

To further explore the catalytic performances of compound 2, different functional group substituted epoxides were employed for $\mathrm{CO}_{2}$ cyclo-addition reaction under optimized reaction conditions. As showed in Table 2, the yields of corresponding cyclic carbonates decreased with the increasing of the alkyl length, which is probably due to the steric hindrance (entries 1-4). The cyclo-addition reactions of 1,2-epoxybutane and epichlorohydrin were catalyzed with high yield (entries 2 and 3), which also demonstrated effective catalytic performance of compound 2. When styrene oxide was used as the reactant, the desired carbonate was generated with $88.4 \%$ yield (entry 4 ). However, the internal epoxide 1,2-epoxycyclohexane was converted to the corresponding cyclic carbonate with low 
yield (43.2\%), which may be attributed to the high steric hindrance of cyclohexene oxide [44]. As a heterogeneous catalyst, recyclability is an essential feature to be considered in industrial applications. The recycling experiments were performed by using propylene oxide as substrate, and the results revealed that there was only $5.8 \%$ decrease of the catalytic activity after four catalytic cycles (Table 1 , entry 9; Figures S6 and S7). The recycled Tb-MOF was characterized by PXRD investigation, and the result showed the framework of compound 2 could be well consistent with original one (Figure S5).

Table 2. Cyclo-addition of $\mathrm{CO}_{2}$ with various substrates ${ }^{[\mathrm{a}]}$.

\begin{tabular}{clll} 
Entry & Substrate & & \\
\hline 1 & & & \\
\hline
\end{tabular}

[a] Reaction conditions: epoxides (20 mmol), compound $2(2 \mathrm{~mol} \%), n-\mathrm{Bu}_{4} \mathrm{NBr}(2.5 \mathrm{~mol} \%), \mathrm{CO}_{2}(1 \mathrm{MPa}), 70{ }^{\circ} \mathrm{C}, 12 \mathrm{~h}$; and ${ }^{[b]}$ determined by ${ }^{1} \mathrm{H}$ NMR spectroscopy.

A possible catalytic mechanism for $\mathrm{Tb}-\mathrm{MOF} / n$ - $\mathrm{Bu}_{4} \mathrm{NBr}$-catalyzed cyclo-addition of epoxides and $\mathrm{CO}_{2}$ was discussed based on reported studies (Scheme 1) [45,46]. The framework of compound 2 could enrich $\mathrm{CO}_{2}$ and epoxides owing to its porous channels, which might be beneficial for the reaction. The Lewis acidic site ( $\mathrm{Tb}$ ions) interacted with the oxygen atom of the epoxide, activating the epoxy ring (Step 1). Then, the $\mathrm{Br}^{-}$nucleophile from $n-\mathrm{Bu}_{4} \mathrm{NBr}$ attacks the less hindered carbon atom of the activated epoxide, promoting the ring opening of the epoxide to form active oxygen anion (Step 2). Subsequently, this active oxygen anion reacted with $\mathrm{CO}_{2}$ to produce alkylcarbonate salt (Step 3). Finally, the alkylcarbonate anion was converted to corresponding cyclic carbonate by ring closure and the co-catalyst $n$ - $\mathrm{Bu}_{4} \mathrm{NBr}$ was regenerated simultaneously (Step 4).

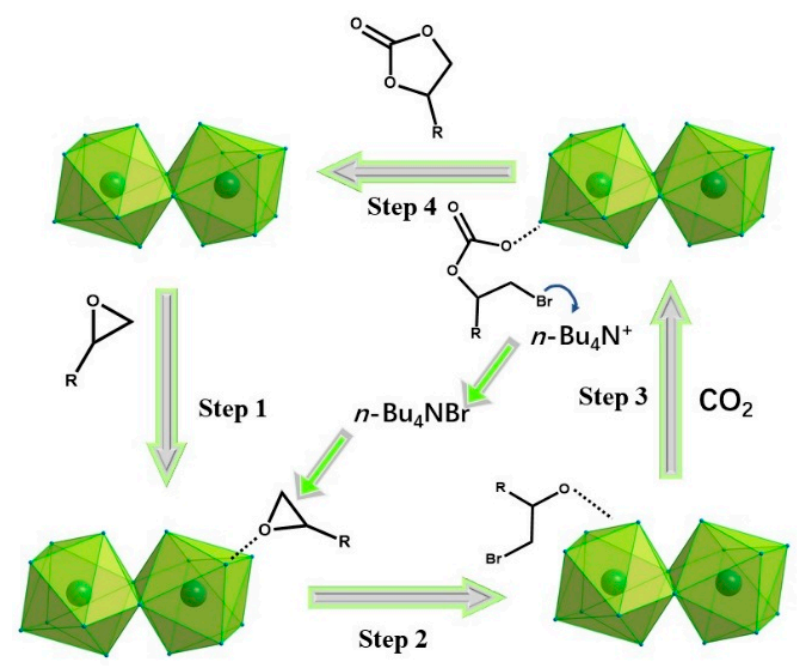

Scheme 1. The proposed mechanism for cyclo-addition reaction of $\mathrm{CO}_{2}$ with epoxides using compound 2 and $n-\mathrm{Bu}_{4} \mathrm{NBr}$ as a co-catalyst. 


\section{Conclusions}

In summary, two novel lanthanide metal-organic frameworks based on semi-rigid tripodal ligand 5-(4-carboxybenzyloxy) isophthalic acid $\left(\mathrm{H}_{3} \mathrm{~L}\right)$ have been solvothermally synthesized and characterized. Compounds $\mathbf{1}$ and 2 are isostructural and possess 3D frameworks with $f l u-3,6-C 2 / c$ structure topology, built from 6-connecting dinuclear metal-carboxylate unit and 3-connecting $\mathrm{L}^{3-}$ ligand. Photoluminescence measurement reveals that compound $\mathbf{1}$ shows near-infrared (NIR) emission, and compound 2 displays a selective fluorescence quenching response to $\mathrm{Cr}(\mathrm{VI})$ anion in liquid suspension. Owing to the accessible Lewis acidic sites in channels, compound 2 could be an efficient heterogeneous catalyst for cyclization reaction with epoxides and $\mathrm{CO}_{2}$, and the recycling number could reach four times without compromising catalytic activity.

Supplementary Materials: The following are available online at http://www.mdpi.com/2073-4360/11/5/868/s1, Materials and Instruments, X-Ray crystallography, Catalytic reactions. Figure S1: TGA profiles of compounds 1 and 2; Figure S2: The emission spectra of ligand $\mathrm{H}_{3} \mathrm{~L}$; Figure S3: Solid state luminescence spectra of compound 2; Figure S4: UV-Vis absorption spectra of compounds 1 and 2 aqueous solutions; Figure S5: The powder XRD patterns of compound 1; Figure S6: The powder XRD patterns of compound 2; Figure S7: Reusability of compound 2 on the PO conversion; Table S1: Crystallographic data and structure refinement details; Table S2: Selected bond lengths $(\AA)$ and angles (deg), ${ }^{1} \mathrm{H}$ NMR characterization data.

Author Contributions: Y.-S.X. designed the experimental section, analyzed the data, and wrote the paper; Z.-L.C. synthesized compounds and carried out the measurements; Y.D. assisted Z.-L.C. to perform the experiment; W.-W.C. assisted Y.-S.X. to analyze the data. All the authors reviewed and approved the paper.

Funding: This research was funded by the National Natural Science Foundation of China (grant 21501147) and Jiangsu Planned Projects for Postdoctoral Research Funds (grant 1701097C).

Conflicts of Interest: The authors declare no conflict of interest.

\section{References}

1. Park, H.D.; Dincă, M.; Román-Leshkov, Y. Continuous-flow production of succinic anhydrides via catalytic $\beta$-lactone carbonylation by $\mathrm{Co}(\mathrm{CO})_{4} \subset \mathrm{Cr}-\mathrm{MIL}-101$. J. Am. Chem. Soc. 2018, 140, 10669-10672. [CrossRef] [PubMed]

2. Dong, X.W.; Yang, Y.; Che, J.X.; Zuo, J.; Li, X.H.; Gao, L.; Hu, Y.Z.; Liu, X.Y. Heterogenization of homogeneous chiral polymers in metal-organic frameworks with enhanced catalytic performance for asymmetric catalysis. Green Chem. 2018, 20, 4085-4093. [CrossRef]

3. Sun, L.; Yun, Y.; Sheng, H.; Du, Y.; Ding, Y.; Wu, P.; Li, P.; Zhu, M. Rational encapsulation of atomically precise nanoclusters into metal-organic frameworks by electrostatic attraction for $\mathrm{CO}_{2}$ conversion. J. Mater. Chem. A 2018, 6, 15371-15376. [CrossRef]

4. Li, Z.; Peters, A.W.; Platero-Prats, A.E.; Liu, J.; Kung, C.W.; Noh, H.; DeStefano, M.R.; Schweitzer, N.M.; Chapman, K.W.; Hupp, J.T. Fine-tuning the activity of metal-organic framework-supported cobalt catalysts for the oxidative dehydrogenation of propane. J. Am. Chem. Soc. 2017, 139, 15251-15258. [CrossRef]

5. Zhang, J.; Huang, Y.; Yue, D.; Cui, Y.; Yang, Y.; Qian, G. A luminescent turn-up metal-organic framework sensor for tryptophan based on singlet-singlet Förster energy transfer. J. Mater. Chem. B 2018, 6, 5174-5180. [CrossRef]

6. Jiang, M.; Li, P.; Wu, P.; Zhang, F.; Tian, X.; Deng, C.; Wang, J. A squaramide-based metal-organic framework as a luminescent sensor for the detection of lactose in aqueous solution and in milk. Chem. Commun. 2018, 54, 9131-9134. [CrossRef]

7. Sun, X.; Yao, S.; Yu, C.; Li, G.; Liu, C.; Huo, Q.; Liu, Y. An ultrastable Zr-MOF for fast capture and highly luminescence detection of $\mathrm{Cr}_{2} \mathrm{O}_{7}{ }^{2-}$ simultaneously in an aqueous phase. J. Mater. Chem. A 2018, 6, 6363-6369. [CrossRef]

8. Marti, A.M.; Venna, S.R.; Roth, E.A.; Culp, J.T.; Hopkinson, D.P. Simple fabrication method for mixed matrix membranes with in situ MOF growth for gas separation. ACS Appl. Mater. Interfaces 2018, 10, 24784-24790. [CrossRef] 
9. Prasetya, N.; Donose, B.C.; Ladewig, B.P. A new and highly robust light-responsive Azo-UiO-66 for highly selective and low energy post-combustion $\mathrm{CO}_{2}$ capture and its application in a mixed matrix membrane for $\mathrm{CO}_{2} / \mathrm{N}_{2}$ separation. J. Mater. Chem. A 2018, 6, 16390-16402. [CrossRef]

10. Zhang, M.; Zhou, W.; Pham, T.; Forrest, K.A.; Liu, W.; He, Y.; Wu, H.; Yildirim, T.; Chen, B.; Space, B. Fine tuning of MOF-505 analogues to reduce low-pressure methane uptake and enhance methane working capacity. Angew. Chem., Int. Ed. 2017, 56, 11426-11430. [CrossRef]

11. Li, B.; Wen, H.M.; Cui, Y.; Zhou, W.; Qian, G.; Chen, B. Emerging multifunctional metal-organic framework materials. Adv. Mater. 2016, 28, 8819-8860. [CrossRef] [PubMed]

12. Meng, X.; Zhang, X.; Bing, Y.; Xu, N.; Shi, W.; Cheng, P. In situ generation of NiO nanoparticles in a magnetic metal-organic framework exhibiting three-dimensional magnetic ordering. Inorg. Chem. 2016, 55, 12938-12943. [CrossRef]

13. Han, J.; Wang, D.; Du, Y.H.; Xi, S.; Hong, J.; Yin, S.; Chen, Z.; Zhou, T.; Xu, R. Metal-organic framework immobilized cobalt oxide nanoparticles for efficient photocatalytic water oxidation. J. Mater. Chem. A 2015, 3, 20607-20613. [CrossRef]

14. Armelaoa, L.; Quici, S.; Barigelletti, F.; Accorsic, G.; Bottaro, G.; Cavazzini, M.; Tondello, E. Design of luminescent lanthanide complexes: From molecules to highly efficient photo-emitting materials. Coord. Chem. Rev. 2010, 254, 487-505. [CrossRef]

15. Eliseeva, S.V.; Bünzli, J.C.G. Lanthanide luminescence for functional materials and bio-sciences. Chem. Soc. Rev. 2010, 39, 189-227. [CrossRef]

16. Joao, R.; Luis, D.C.; Filipe, A.A.P.; Duarte, A. Luminescent multifunctional lanthanides-based metal-organic frameworks. Chem. Soc. Rev. 2011, 40, 926-940.

17. White, K.A.; Chengelis, D.A.; Gogick, K.A.; Stehman, J.; Rosi, N.L.; Petoud, S. Near-Infrared Luminescent Lanthanide MOF Barcodes. J. Am. Chem. Soc. 2009, 131, 18069-18071. [CrossRef]

18. Chen, B.L.; Wang, L.B.; Zapata, F.; Qian, G.D.; Lobkovsky, E.B. A luminescent microporous metal-organic framework for the recognition and sensing of anions. J. Am. Chem. Soc. 2008, 130, 6718-6719. [CrossRef]

19. Dou, Z.S.; Yu, J.C.; Cui, Y.J.; Yang, Y.; Wang, Z.Y.; Yang, D.; Qian, G.D. Luminescent metal-organic framework films as highly sensitive and fast-response oxygen sensors. J. Am. Chem. Soc. 2014, 136, 5527-5530. [CrossRef]

20. Zhao, Y.; Tian, J.S.; Qi, X.H.; Han, Z.N.; Zhuang, Y.Y.; He, L.N. Quaternary ammonium salt-functionalized chitosan: An easily recyclable catalyst for efficient synthesis of cyclic carbonates from epoxides and carbon dioxide. J. Mol. Catal. A 2007, 271, 284-289. [CrossRef]

21. Yang, J.; Song, S.Y.; Ma, J.F.; Liu, Y.Y.; Yu, Z.T. Syntheses, structures, photoluminescence, and gas adsorption of rare earth-organic frameworks based on a flexible tricarboxylate. Cryst. Growth Des. 2011, 11, 5469-5474. [CrossRef]

22. Chai, X.C.; Sun, Y.Q.; Lei, R.; Chen, Y.P.; Zhang, S.; Cao, Y.N.; Zhang, H.H. A series of lanthanide frameworks with a flexible ligand, $\mathrm{N}, \mathrm{N}^{\prime}$-diacetic acid imidazolium, in different coordination modes. Cryst. Growth Des. 2010, 10, 658-668. [CrossRef]

23. Spek, A.L. Single-crystal structure validation with the program PLATON. J. Appl. Crystallogr. 2003, 36, 7. [CrossRef]

24. Blatov, V.A. TOPOS, A Multipurpose Crystallochemical Analysis with the Program Package; Samara State University: Samara Oblast, Russia, 2004.

25. Lakowicz, J.R. Principles of Fluorescence Spectroscopy, 3rd ed.; Springer: Berlin, Germany, 2006; pp. 63-95.

26. Valeur, B. Molecular Fluorescence: Principles and Application; Wiley-VCH: Weinheim, Germany, 2002; pp. 34-70.

27. Chen, G.Y.; Ohulchanskyy, T.Y.; Liu, S.; Law, W.C.; Wu, F.; Swihart, M.T.; Agren, H.; Prasad, P.N. Core/Shell $\mathrm{NaGdF}_{4}: \mathrm{Nd}^{3+} / \mathrm{NaGdF}_{4}$ nanocrystals with efficient near-infrared to near-infrared downconversion photoluminescence for bioimaging applications. ACS Nano 2012, 6, 2969-2977. [CrossRef]

28. Marciniak, L.; Strek, W.; Guyot, Y.; Hreniak, D.; Boulon, G. Synthesis and $\mathrm{Nd}^{3+}$ luminescence properties of $\mathrm{ALa}_{1-\mathrm{x}} \mathrm{Nd}_{x} \mathrm{P}_{4} \mathrm{O}_{12}(\mathrm{~A}=\mathrm{Li}, \mathrm{Na}, \mathrm{K}, \mathrm{Rb})$ tetraphosphate nanocrystals. J. Phys. Chem. C 2015, 119, 5160-5167. [CrossRef]

29. Cui, Y.; Xu, H.; Yue, Y.; Guo, Z.; Yu, J.; Chen, Z.; Gao, J.; Yang, Y.; Qian, G.; Chen, B. A luminescent mixed-lanthanide metal-organic framework thermometer. J. Am. Chem. Soc. 2012, 134, 3979-3982. [CrossRef] [PubMed] 
30. Lu, W.G.; Jiang, L.; Feng, X.L.; Lu, T.B. Three-dimensional lanthanide anionic metal-organic frameworks with tunable luminescent properties induced by cation exchange. Inorg. Chem. 2009, 48, 6997-6999. [CrossRef] [PubMed]

31. Zhao, J.; Wang, Y.N.; Dong, W.W.; Wu, Y.P.; Li, D.S.; Zhang, Q.C. A Robust Luminescent Tb(III)-MOF with Lewis Basic Pyridyl Sites for the Highly Sensitive Detection of Metal Ions and Small Molecules. Inorg. Chem. 2016, 55, 3265-3271. [CrossRef]

32. Xue, Y.S.; Shi, D.; Zhang, H.; Ju, W.; Mei, H.; Xu, Y. A series of color-tunable light-emitting open-framework lanthanide sulfates containing extra-large 36-membered ring channels. CrystEngComm 2017, 19, 5989-5994. [CrossRef]

33. Zhao, X.L.; Tian, D.; Gao, Q.; Sun, H.W.; Xu, J.; Bu, X.H. A chiral lanthanide metal-organic framework for selective sensing of Fe(III) ions. Dalton Trans. 2016, 45, 1040-1046. [CrossRef]

34. Yang, J.; Yue, Q.; Li, G.D.; Cao, J.J.; Li, G.H.; Chen, J.S. Structures, photoluminescence, up-conversion, and magnetism of $2 \mathrm{D}$ and $3 \mathrm{D}$ rare-earth coordination polymers with multicarboxylate linkages. Inorg. Chem. 2006, 45, 2857-2865. [CrossRef] [PubMed]

35. Dong, X.Y.; Wang, R.; Wang, J.Z.; Zang, S.Q.; Mak, T.C.W. Highly selective Fe3+ sensing and proton conduction in a water-stable sulfonate-carboxylate Tb-organic-framework. J. Mater. Chem. A 2015, 3, 641-647. [CrossRef]

36. Xue, Y.S.; He, Y.; Zhou, L.; Chen, F.J.; Xu, Y.; Du, H.B.; You, X.Z.; Chen, B. A photoluminescent microporous metal organic anionic framework for nitroaromatic explosive sensing. J. Mater. Chem. A 2013, 1, 4525-4530. [CrossRef]

37. Chen, B.; Wang, L.; Xiao, Y.; Fronczek, F.R.; Xue, M.; Cui, Y.; Qian, G. A luminescent metal-organic framework with Lewis basic pyridyl sites for the sensing of metal ions. Angew. Chem. Int. Ed. 2009, 48, 500-503. [CrossRef] [PubMed]

38. Xu, H.; Cao, C.S.; Zhao, B. A water-stable lanthanide-organic framework as a recyclable luminescent probe for detecting pollutant phosphorus anions. Chem. Commun. 2015, 51, 10280-10283. [CrossRef] [PubMed]

39. Dong, J.; $\mathrm{Xu}, \mathrm{H}$; $\mathrm{Hou}$, S.L.; Wu, Z.L.; Zhao, B. Metal-organic frameworks with $\mathrm{Tb}_{4}$ clusters as nodes: Luminescent detection of chromium(VI) and chemical fixation of $\mathrm{CO}_{2}$. Inorg. Chem. 2017, 56, 6244-6250. [CrossRef]

40. Wojtas, L.; Cai, J.; Chen, Y.S.; Ma, S. Crystal engineering of an nbo topology metal-organic framework for chemical fixation of $\mathrm{CO}_{2}$ under ambient conditions. Angew. Chem. Int. Ed. 2014, 53, 2615-2619.

41. Gao, W.Y.; Wojtas, L.; Ma, S.Q. A porous metal-metalloporphyrin framework featuring high-density active sites for chemical fixation of $\mathrm{CO}_{2}$ under ambient conditions. Chem. Commun. 2014, 50, 5316-5318. [CrossRef]

42. Gao, W.Y.; Tsai, C.Y.; Wojtas, L.; Thiounn, T.; Lin, C.C.; Ma, S. Interpenetrating metal-metalloporphyrin framework for selective $\mathrm{CO}_{2}$ uptake and chemical transformation of $\mathrm{CO}_{2}$. Inorg. Chem. 2016, 55, 7291-7294. [CrossRef]

43. Song, L.; Chen, C.; Chen, X.; Zhang, N. Isomorphic MOFs functionalized by free-standing acylamide and organic groups serving as self-supported catalysts for the $\mathrm{CO}_{2}$ cycloaddition reaction. New J. Chem. 2016, 40, 2904-2909. [CrossRef]

44. Sakai, T.; Tsutsumi, Y.; Ema, T. Highly active and robust organic-inorganic hybrid catalyst for the synthesis of cyclic carbonates from carbon dioxide and epoxides. Green Chem. 2008, 10, 337-341. [CrossRef]

45. Li, P.Z.; Wang, X.J.; Liu, J.; Lim, J.S.; Zou, R.; Zhao, Y. A triazole-containing metal-organic framework as a highly effective and substrate size-dependent catalyst for $\mathrm{CO}_{2}$ conversion. J. Am. Chem. Soc. 2016, 138, 2142-2145. [CrossRef] [PubMed]

46. Kathalikkattil, A.C.; Roshan, R.; Tharun, J.; Babu, R.; Jeong, G.S.; Kim, D.W.; Cho, S.J.; Park, D.W. A sustainable protocol for the facile synthesis of zinc-glutamate MOF: An efficient catalyst for room temperature $\mathrm{CO}_{2}$ fixation reactions under wet conditions. Chem. Commun. 2016, 52, 280-283. [CrossRef] [PubMed]

(C) 2019 by the authors. Licensee MDPI, Basel, Switzerland. This article is an open access article distributed under the terms and conditions of the Creative Commons Attribution (CC BY) license (http://creativecommons.org/licenses/by/4.0/). 